\title{
Antibody response against Escherichia coli heat-stable enterotoxin expressed as fusions to flagellin
}

\author{
Cátia M. Pereira, ${ }^{1}$ Beatriz E. Cabilio Guth, ${ }^{1}$ \\ Maria Elisabete Sbrogio-Almeida ${ }^{2}$ and Beatriz A. Castilho
}

Author for correspondence: Cátia M. Pereira. Tel: +55 115084 3213. Fax: +55 115716504.

e-mail: pereiracm@hotmail.com

\footnotetext{
1 Departamento de Microbiologia, Imunologia e Parasitologia, Escola Paulista de Medicina, Universidade Federal de São Paulo, Rua Botucatu, 862, CEP 04023-062, São Paulo, Brazil

2 Divisão de Desenvolvimento Tecnológico e Produção, Instituto Butantan, Avenida Vital Brasil 1500, CEP 05503-900, São Paulo, Brazil
}

\begin{abstract}
The heat-stable toxin (ST) produced by enterotoxigenic Escherichia coli strains causes diarrhoea by altering the fluid secretion in intestinal epithelial cells. Here, the effectiveness of a flagellin fusion protein of Salmonella containing a 19-amino-acid sequence derived from the ST sequence (FLA-ST) in generating antibodies capable of neutralizing the toxic activity of ST was evaluated. This fusion protein, and an alternative construction where two cysteine residues in the ST sequence were substituted by alanines $\left(\mathrm{ST}_{\mathrm{mt}}\right)$, were delivered to the immune system by three distinct strategies: (i) orally, using an attenuated Salmonella strain expressing FLA-ST; (ii) intraperitoneally, by injection of purified FLA-ST; (iii) orally, using attenuated Salmonella carrying a eukaryotic expression plasmid (pCDNA3) with the gene encoding FLA-ST. The results showed that the flagellin system can be used as a carrier to generate ST-neutralizing antibodies. However, it should be mentioned that humoral immune response against ST was only obtained when the mutated ST sequence was employed. FLA-ST was found to be non-immunogenic when delivered via the oral route with attenuated Salmonella strains. However, a flagellin antibody response was obtained by immunizing mice with Salmonella carrying

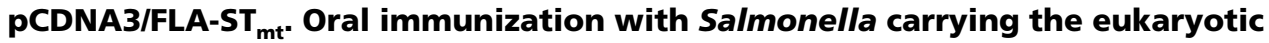

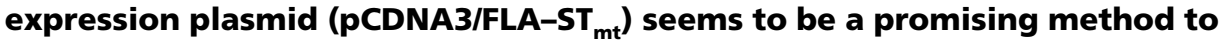
elicit an appropriate response against fusions to flagellin.
\end{abstract}

Keywords: ETEC, ST, attenuated Salmonella, flagellin fusions, mucosal vaccines

\section{INTRODUCTION}

The virulence of enterotoxigenic Escherichia coli (ETEC) strains, an important cause of diarrhoea in children in developing countries and travellers to these areas (Black, 1990, 1993), is directly related to the production of heat-labile (LT) and/or heat-stable (ST) toxins, which alter the hydrosaline balance of the intestinal mucosa. ST acts by stimulating guanylate cyclase in intestinal epithelial cells; the rise of cGMP ultimately results in extensive fluid secretion. The primary structure of ST has been determined and its full enterotoxigenic activity has been found to be expressed by a segment of 13 amino acid residues, which includes six cysteines linked by three disulfide bonds (Okamoto

Abbreviations: ETEC, enterotoxigenic Escherichia coli; OPD, o-phenylenediamine dihydrochloride. et al., 1987; Shimonishi et al., 1987; Yamasaki et al., 1988; Yoshimura et al., 1985).

Several lines of evidence have indicated that protection against ETEC diarrhoea involves anti-toxin and antibacterial components. ST is a non-immunogenic lowmolecular-mass peptide $(2 \mathrm{kDa})$; however, its conjugation to different carriers can lead to the induction of neutralizing antibodies. Recently, a number of efforts have been made to render ST immunogenic, including chemical coupling and genetic fusions to appropriate carrier proteins (Clements, 1990; Houghten et al., 1984, 1985; Klipstein et al., 1982, 1983; Sanchez et al., 1986, 1988). In general, chemical coupling reduced ST-associated toxicity as a function of the cross-linking and maintained the immunological determinants of ST. Genetic fusions have, as an advantage, the possibility of being delivered by live attenuated bacterial strains to elicit antibody response on the mucosal surfaces. Fusion 
between ST and LT resulted in a non-toxic and immunogenic molecule, capable of eliciting neutralizing antibodies against ST (Clements, 1990). Moreover, sera and mucosal secretions from mice immunized orally with an attenuated Salmonella strain carrying this genetic fusion were able to neutralize the biological activity of native ST in the suckling mouse assay, but, surprisingly, in the absence of detectable ELISA antibody titres against ST (Cárdenas \& Clements, 1993). The OmpC outer-membrane protein of E. coli has also been used as a carrier for $\mathrm{ST}$, and antibody responses to ST and OmpC proteins were elicited in rabbits immunized subcutaneously with whole cells expressing the hybrid protein; however, these antibodies were not able to neutralize the ST toxic activity (Saarilahti et al., 1989).

Attenuated Salmonella represents an attractive vector for the delivery of heterologous antigens to the immune system. Salmonella can be rendered avirulent, for example, by the inactivation of genes involved in the biosynthesis of aromatic compounds. A number of antigens have been expressed by these attenuated strains in attempts to construct bivalent vaccines. Heterologous epitopes have also been expressed as fusions to the Salmonella flagellin, a system developed to expose epitopes on the bacterial surface, as part of the flagellar filament (Newton et al., 1989, 1991, 1995; Wu et al., 1989). Attenuated bacterial strains have also been used as carriers for DNA delivery in vivo, because of their ability to deliver the antigen-encoding DNA specifically to antigen-presenting cells at inductive sites of immune response (Darji et al., 1997; Paglia et al., 1998; Sizemore et al., 1995, 1997).

In this study, the flagellin system was used to present ST sequences to the immune system in order to obtain ST neutralizing antibodies. A sequence with 19 amino acids derived from the native ST toxin and an identical sequence except for two mutations that replace two cysteine residues by alanines were fused to flagellin, and delivered intraperitoneally as purified protein, or orally by attenuated Salmonella strains expressing the fusion protein or carrying a eukaryotic expression vector containing the fusion. The ability of these forms of presentation of the ST sequences to the immune system to elicit an immune response against ST is presented.

\section{METHODS}

Bacterial strains and plasmids. Bacterial strains and plasmids used in this work are shown in Table 1. Luria broth and Luria agar supplemented with $100 \mu \mathrm{g}$ ampicillin $\mathrm{ml}^{-1}$ were used for the growth of bacteria. Plasmid pLS408 is a pUC19 derivative carrying the $f l i C(\mathrm{~d})$ gene (formerly called $\mathrm{H}-1$ ) from Salmonella muenchen with a 48 bp EcoRV fragment deletion in the central hypervariable region (region IV) of the flagellin gene (Newton et al., 1989). The eukaryotic expression vector CDNA3 (Invitrogen) was used for cloning the flagellin gene containing the $\mathrm{ST}_{\mathrm{mt}}$ (mutant ST) fragment.

Synthetic oligonucleotides and insertions in the flagellin gene. Complementary oligonucleotide pairs corresponding to the ST wild-type $\left(\mathrm{ST}_{\mathrm{wt}}\right)$ sequence $\left({ }^{1} \mathrm{NSSNYCCELCCNPAC-}\right.$
$\mathrm{TGCY}^{19}$ ) or to a mutant ST $\left(\mathrm{ST}_{\mathrm{mt}}\right)$ ( $\mathrm{Cys}^{7} \mathrm{Ala}$ and $\left.\mathrm{Cys}{ }^{18} \mathrm{Ala}\right)$ sequence were inserted in the central, hypervariable, region of the $f l i C(\mathrm{~d})$ flagellin gene at the EcoRV site of vector pLS408. The oligonucleotide for the coding strand of $\mathrm{ST}_{\mathrm{wt}}$ was $5^{\prime}$ ATCAATTCTTCTAAC TACTGCTGTGAACTTTGTTGTAATCCTGCCTGTACA GGATGTTACGTA-3' and of

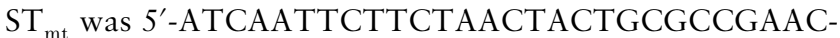
TTTGTTGTAATCCTGCCTGTACAGGAGCCTACGTA- 3'. The insertions were sequenced using a 15 -mer primer complementary to nucleotides located $26 \mathrm{bp}$ upstream from the EcoRV insertion site in the $f l i C$ gene. The plasmids containing the ST inserts in the correct orientation were introduced into the Salmonella enterica serovar Typhimurium strain LB5000 and then transferred to S. enterica serovar Dublin strain SL5928.

Cloning the flagellin gene into the eukaryotic expression vector pCDNA3. For the construction of the eukaryotic expression vector pCDNA3 carrying the hybrid flagellin gene, a $1.8 \mathrm{~kb}$ EcoRI-Sau3AI fragment containing the flagellin gene with the $\mathrm{ST}_{\mathrm{mt}}$ sequence was isolated from plasmid $\mathrm{pLS} 408 / \mathrm{ST}_{\mathrm{mt}}$, and was inserted in the EcoRI and BamHI sites of vector pCDNA3. The resulting plasmid, pCDNA3/ $\mathrm{FLA}_{-} \mathrm{ST}_{\mathrm{mt}}$, was introduced into the Salmonella typhimurium strain LB5000 and transferred to S. typhimurium strain SL3261.

Detection of the hybrid flagellins. Flagellin, purified by acid cleavage as described by Ibrahim et al. (1985), and bacterial cell lysates were separated on $10 \%$ SDS-PAGE gels. The proteins were transferred to nitrocellulose filters (Hybond-C Extra; Amersham) at $1 \mathrm{~A}$ for $2 \mathrm{~h}$ using the buffer conditions described by Towbin et al. (1979). The membranes were blocked with $5 \%$ low-fat milk in PBS for $1 \mathrm{~h}$ at room temperature, and incubated for $1 \mathrm{~h}$ with rabbit antiserum against Salmonella flagellar antigen d (Difco). After washings with $0.05 \%$ Tween 20 in PBS (PBS-T), bound antibodies were reacted with goat anti-rabbit IgG conjugated with peroxidase (Sigma). After incubation for $1 \mathrm{~h}$ with the conjugate and washings in PBS-T, bound antibodies were detected using the ECL detection system (Amersham).

Immunizations. BALB/c mice, 6-8 weeks old, were immunized intraperitoneally with $10 \mu \mathrm{g}$ purified flagellin added to $500 \mu \mathrm{g}$ aluminium hydroxide as adjuvant on days 0,21 and 35. Sera samples were obtained $28 \mathrm{~d}$ after the initial immunization and $7 \mathrm{~d}$ after the last booster. For oral immunization, $10^{10}$ c.f.u. of live $S$. typhimurium resuspended in $0 \cdot 2 \mathrm{M} \mathrm{NaHCO}_{3}$ were fed to 8-12-week-old mice on days 0,21 and 35 , and fecal and sera samples from immunized animals were obtained $7 \mathrm{~d}$ after the second and last doses. These groups of mice received one additional dose each on day 65 , and fecal and sera samples were collected $7 \mathrm{~d}$ after final inoculation. Groups of BALB/c mice, 6-8 weeks old, were also immunized in the leg muscle with four doses of $100 \mu \mathrm{g}$ CsCl-purified plasmid pCDNA3/FLA-ST ${ }_{\mathrm{mt}}$, diluted in $50 \mu \mathrm{l}$ PBS, at $14 \mathrm{~d}$ intervals. Serum samples were obtained $7 \mathrm{~d}$ after the second, third and fourth doses.

Analyses of serum antibodies (ELISA). Microplates (Nunc) were coated with $100 \mathrm{ng}$ purified flagellin per well and incubated at $4{ }^{\circ} \mathrm{C}$ overnight. The wells were washed three times with PBS-T and blocked with $5 \%$ low-fat milk for $1 \mathrm{~h}$ at $37^{\circ} \mathrm{C}$. Different dilutions of mice sera were added and the plates were incubated for $1 \mathrm{~h}$ at $37^{\circ} \mathrm{C}$. Washes with PBS-T were performed, anti-mouse IgG-peroxidase conjugate was added and incubation was continued for $1 \mathrm{~h}$ at $37^{\circ} \mathrm{C}$, prior to development with OPD (o-phenylenediamine dihydrochloride) and $\mathrm{H}_{2} \mathrm{O}_{2}$ as enzyme substrate. Detection of antibodies 
Table 1. Bacterial strains and plasmids

\begin{tabular}{|c|c|c|}
\hline Bacterial strain or plasmid & Relevant characteristics & Reference \\
\hline \multicolumn{3}{|l|}{ Strains } \\
\hline Escherichia coli $\mathrm{DH} 5 \alpha$ & $\operatorname{lac} Z$ & Laboratory stock \\
\hline Escherichia coli (ETEC) PB176 & $\mathrm{STa}$ & Evans \& Evans (1978) \\
\hline Escherichia coli $\mathrm{C} 600$ & K-12 & Laboratory stock \\
\hline Salmonella typhimurium LB500 & $\mathrm{r}^{-} \mathrm{m}^{+}$ & Sanderson \& Stocker (1987) \\
\hline Salmonella typhimurium SL3261 & $\operatorname{aro} A$ & Hoiseth \& Stocker (1981) \\
\hline Salmonella dublin SL5928 & $\operatorname{aro} A$ fliC: $: \operatorname{Tn} 10$ & Newton et al. (1989) \\
\hline Salmonella dublin SL5930 & aro A fliC:: Tn10, pLS408 & Newton et al. (1989) \\
\hline \multicolumn{3}{|l|}{ Plasmids } \\
\hline pLS408 & $\begin{array}{l}\text { pUC19 derivative carrying gene } f l i C(\mathrm{~d}) \text { from Salmonella } \\
\text { muenchen with a } 48 \text { bp deletion and unique EcoRV site }\end{array}$ & Newton et al. (1989) \\
\hline $\mathrm{pLS} 408 / \mathrm{ST}_{\mathrm{wt}}$ & pLS408 derivative with the ST portion coding insert & This study \\
\hline $\mathrm{pLS} 408 / \mathrm{ST}_{\mathrm{mt}}$ & pLS408 derivative with the mutated ST portion coding insert & This study \\
\hline pCDNA3 & Eukaryotic expression vector & Invitrogen \\
\hline $\mathrm{pCDNA} 3 / \mathrm{FLA}-\mathrm{ST}_{\mathrm{mt}}$ & pCDNA3 derivative with the mutated ST portion coding insert & This study \\
\hline
\end{tabular}

against ST was performed as described by Svennerholm et al. (1986). Alternatively, microplates were coated with the ganglioside GM1 (Sigma) $\left(1 \mathrm{mg} \mathrm{ml}^{-1}\right)$ diluted in PBS and incubated at $4{ }^{\circ} \mathrm{C}$ overnight. The wells were blocked with $0 \cdot 1 \%$ BSA-PBS for $30 \mathrm{~min}$ at room temperature. ST coupled to the purified $\beta$ subunit of cholera toxin $\left(\mathrm{ST}-\mathrm{CT}_{\mathrm{B}}\right.$ ) (a gift from Dr A.-M. Svennerholm, Göteborg University, Sweden), $500 \mathrm{ng} \mathrm{ST} \mathrm{ml}{ }^{-1}$, diluted in PBS was added and incubation was continued for $1 \mathrm{~h}$ at room temperature. Different dilutions of mice antisera were added and plates were incubated for $1 \mathrm{~h}$ at $37^{\circ} \mathrm{C}$. Washes with PBS-T were performed, anti-mouse IgG conjugate was added and incubation was continued for $1 \mathrm{~h}$ at $37{ }^{\circ} \mathrm{C}$, prior to development with OPD and $\mathrm{H}_{2} \mathrm{O}_{2}$ as enzyme substrate.

Inhibition ELISA. Sera from mice immunized with purified flagellin were pre-incubated with supernatants of overnight cultures, in Casamino acids/yeast extract (CAYE), of ETEC strain PB176 (STa), or of E. coli K-12 C600 as a negative control, and added to microtitre plate wells previously coated with GM1 (1 mg ml$\left.{ }^{-1}\right)$ and ST-CT ${ }_{\mathrm{B}}$ conjugate. Washes with PBS were performed and bound antibodies were reacted with goat anti-mouse IgG conjugated with peroxidase and developed with OPD and $\mathrm{H}_{2} \mathrm{O}_{2}$.

Neutralization of the ST toxic activity. The suckling mouse assay for ST was performed as described by Giannella (1976). Mice (1-3 d old) were inoculated intragastrically with $0 \cdot 1 \mathrm{ml}$ CAYE supernatant of ETEC strain PB176 previously incubated with sera from immunized mice, for $1 \mathrm{~h}$ at $37^{\circ} \mathrm{C}$. After $3 \mathrm{~h}$ inoculation, mice were killed, the intestines were removed and the ratios between the weights of the guts and of the remaining carcasses were calculated. Gut/carcass ratios of $\geqslant 0.082$ were considered positive.

\section{RESULTS}

\section{Expression of ST as fusions to Salmonella flagellin}

Sequences encoding the native ST toxin were inserted in the central, hypervariable, region of the flagellin gene $f l i C(d)$ at the EcoRV site of plasmid pLS408. A mutant derivative of ST, where $\mathrm{Cys}^{7}$ and $\mathrm{Cys}^{18}$ were replaced by alanines, was also constructed by oligonucleotide in- sertion in the same site of flagellin. This mutant version was employed in order to abolish, or decrease, a possible toxicity of the ST molecule. The plasmids were introduced in the attenuated Salmonella dublin strain SL5928, which does not express wild-type flagellin, in order to express and purify the hybrid flagellins. Hybrid proteins of the expected molecular mass for both constructions were detected in whole cells at approximately the same levels as the flagellin without insert (Fig. 1a). Cells carrying the hybrid flagellins were non-motile in semi-solid Luria medium. Because the complex structure of ST could be interfering with the assembly of the flagellum, bacterial agglutination assays were performed using anti-flagellin antibodies to verify the presence of the flagellum on the cell surface. This serum agglutinated strains expressing the hybrid flagellins (data not shown), indicating that the flagellins were present on the surface of the bacteria.

\section{Immunogenicity of purified ST-flagellin fusions}

To determine whether ST-flagellin could behave as a strong immunogen, the flagellins were purified from the Salmonella strains SL5930, SL5928/ST ${ }_{\mathrm{wt}}$ and SL5928/ $\mathrm{ST}_{\mathrm{mt}}$ (Fig. 1b, c) and used to inoculate mice intraperitoneally. Sera from immunized mice showed high ELISA titres against flagellin (Table 2). Furthermore, high ELISA titres against ST were also detected in sera from mice immunized with FLA-ST mt $_{\text {(purified flagellin }}$ containing the mutated ST sequences) (Table 2). The ability of antibodies generated against FLA-ST $\mathrm{mt}_{\mathrm{t}}$ to recognize the native ST toxin produced by ETEC strain PB176 was evaluated in inhibition ELISA tests. The binding of antibodies generated after immunization with the hybrid flagellin to solid-phase-bound ST-CT ${ }_{B}$ conjugate was partially inhibited after incubation in the presence of ST-positive culture supernatant (Fig. 2). Moreover, sera from mice immunized with the purified FLA-ST ${ }_{m t}$ were able to partially neutralize the bio- 
(a)

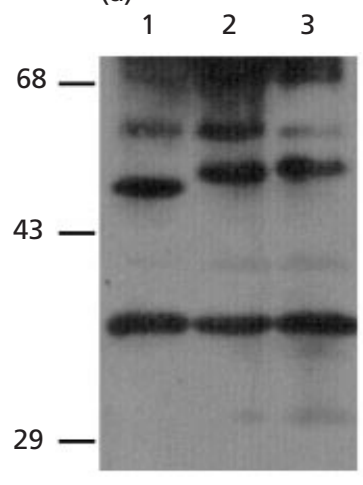

(b)

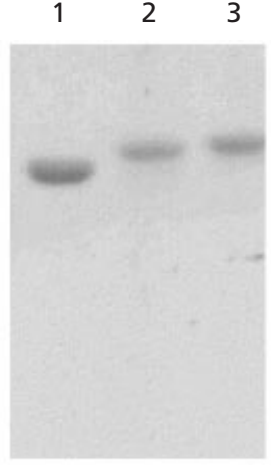

(c)

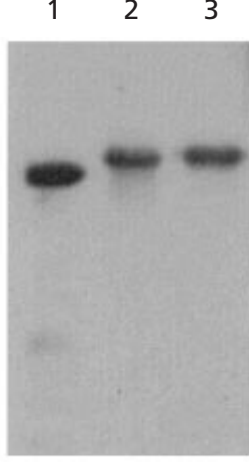

Fig. 1. Detection and purification of the hybrid flagellins. (a) Immunoblot of wholecell extracts of $S$. dublin expressing the wildtype flagellin (lane 1) and the FLA-ST wt $_{\text {(lane }}$ 2) and FLA-ST ${ }_{m t}$ (lane 3) hybrid flagellins, reacted with an antiserum against flagellin.

(b) Coomassie blue staining of $10 \%$ SDSPAGE of the purified flagellins. (c) Immunoblot of purified flagellins using anti-flagellin antibodies. Molecular mass standards are indicated in $\mathrm{kDa}$ on the left.
Table 2. Mice IgG antibody responses against flagellin and ST

Mice were immunized intraperitoneally with flagellins or intramuscularly with pCDNA3/FLA-ST ${ }_{\mathrm{mt}}$. ELISA titres represent means of the reciprocal of the titres \pm SD of pooled mice sera. Mice pre-immune sera were used as negative controls. An $A_{492}$ value two times above the control sera was defined as positive.

\begin{tabular}{|lcc|}
\hline \multirow{2}{*}{ Antigen } & \multicolumn{2}{c|}{ Serum antibody titre } \\
\cline { 2 - 3 } & Flagellin & ST \\
\hline FLA-30 & $156214 \pm 5764$ & $<50$ \\
FLA-ST $_{\mathrm{wt}}$ & $145753 \pm 3979$ & $<50$ \\
FLA-ST $_{\mathrm{mt}}$ & $96874 \pm 2524$ & $3937 \pm 191$ \\
pCDNA3/FLA-ST $_{\mathrm{mt}}$ & $1679 \pm 216$ & $<50$ \\
\hline
\end{tabular}

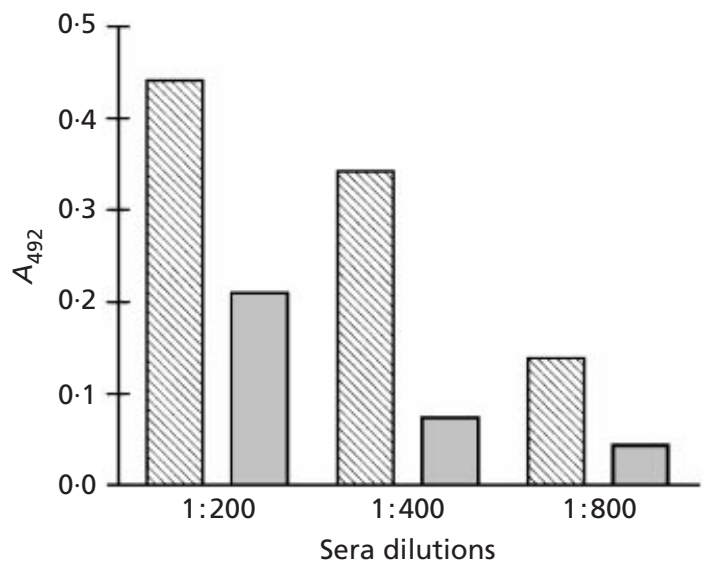

Fig. 2. Inhibition ELISA. Sera from mice immunized with $\mathrm{FLA}_{\mathrm{ST}} \mathrm{mt}_{\mathrm{m}}$ were pre-incubated with the supernatant of an overnight culture of ETEC strain PB176 (STa) (shaded bars) or of $E$. coli K-12 C600 (striped bars), as negative control, and added to microtitre plate wells previously coated with $\mathrm{GM} 1\left(2 \mathrm{mg} \mathrm{ml}^{-1}\right)$ and incubated with $\mathrm{ST}-\mathrm{CT}_{\mathrm{B}}$ conjugate. The results are means of duplicates. Standard deviations were never greater than $10 \%$ above or below the mean.

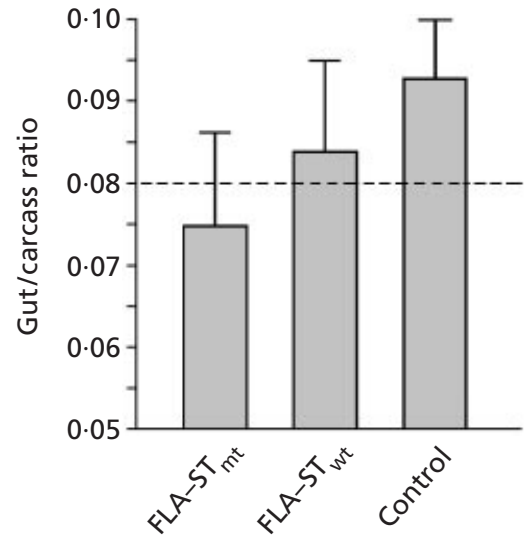

Fig. 3. Neutralization of the ST toxic activity. The CAYE supernatant of ETEC strain PB176 (diluted 1:2) was incubated with sera from immunized mice (diluted $1: 5$ ), for $1 \mathrm{~h}$ at $37^{\circ} \mathrm{C}$, prior to inoculation in suckling mice. Gut/carcass ratios of $\geqslant 0.082$ are considered positive. Values are means \pm SD of four independent experiments performed with four or five mice in each group.

logical activity of the native ST in the suckling mice assay (Fig. 3).

\section{Immunogenicity of FLA-ST ${ }_{\mathrm{mt}}$ expressed in eukaryotic cells}

We showed that mice immunized parenterally with the purified recombinant flagellin FLA-ST $\mathrm{mt}_{\mathrm{m}}$ developed neutralizing antibodies against ST. However, the desired mucosal immune response probably could not be achieved by this route of immunization and, as was reported in a previous work and confirmed here (data not shown), chimeric flagellins were not capable of eliciting an immune response when carried by Salmonella strains in oral immunization (Almeida et al., 1999). The expression of the hybrid flagellin inside the antigen-presenting cells at gut-associated lymphoid tissues could be an alternative approach to improve the stimulation of specific antibody responses following oral administration. Therefore, an S. typhimurium strain carrying the flagellin gene with the mutated ST 


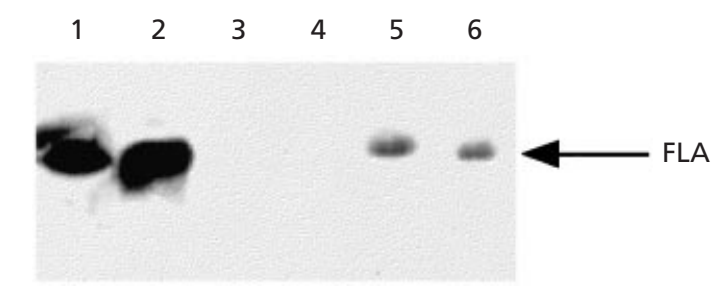

Fig. 4. Immune response induced by FLA-ST expressed in eukaryotic cells. Western blot analyses using purified flagellin of sera from mice immunized intramuscularly with vector

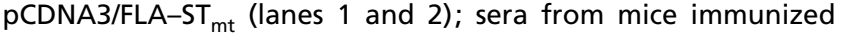
orally with SL3261 carrying PCDNA3 (lanes 3 and 4); sera from mice immunized orally with SL3261 carrying pCDNA3/FLA-ST ${ }_{m t}$ (lanes 5 and 6).

insert under the control of a eukaryotic promoter in

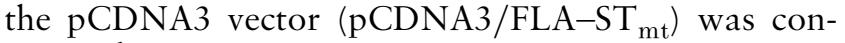
structed.

In order to verify the expression of the chimeric flagellin encoded by the plasmid pCDNA3/FLA-ST ${ }_{m t}$, mice were initially immunized intramuscularly with the purified plasmid DNA. Antibodies against flagellin were detected in sera from mice immunized with four doses of DNA (Table 2). No antibody response was detected against ST. The anti-flagellin ELISA titre obtained was significantly lower than those obtained with intraperitoneal injections of the purified flagellin. This titre difference may explain the absence of detectable antibodies against ST in mice immunized with pCDNA3/FLA-ST ${ }_{m t}$ intramuscularly. However, these results indicated that the antigen was being expressed in eukaryotic cells, and that the construct could be employed with the attenuated live Salmonella.

Mice were then fed with live S. typhimurium carrying pCDNA3/FLA-ST $\mathrm{mt}_{\mathrm{m}}$ and the sera of these animals were tested for the presence of antibodies against flagellin. Because of the high anti-LPS antibodies generated by immunizations with intact bacterial cells, sera from immunized mice were tested in Western blot assays with purified flagellin to avoid mistaken interpretations given by the ELISA assays using flagellin preparations which could contain some LPS contaminants. An antibody response against flagellin was detected in sera from these immunized mice, as revealed by Western blotting (Fig. 4). These sera tested negative for reactivity against ST in ELISA (data not shown). This was expected given the low titres obtained for flagellin. However, these results indicate that this alternative route of oral delivery of flagellin seems to overcome the inherent lack of antigenicity of flagellin when presented by bacteria in oral immunizations.

\section{DISCUSSION}

ST enterotoxin is an important virulence factor of ETEC strains and has been frequently identified among ETEC strains isolated from children with diarrhoeal disease in Brazil (Gomes et al., 1991; Guth \& Trabulsi, 1985; Reis et al., 1982). The small size and poor immunogenicity of the ST molecule have, however, hampered the development of a toxoid suitable for immunization against ETEC. In this study, sequences with 19 amino acids derived from the ST toxin were expressed as fusions to flagellin. Intraperitoneal immunizations with purified chimeric flagellins elicited neutralizing antibodies to ST, indicating that fusions to flagellin can render ST immunogenic. It is noteworthy that the humoral immune response against ST was obtained only when a mutated ST sequence $\left(\mathrm{Cys}^{7}\right.$ and $\mathrm{Cys}^{18}$ replaced by alanines) was inserted in the flagellin. As previously reported, antigenicity and immunogenicity of ST in the genetic fusion with LT were obtained only when an appropriate proline-containing linker was inserted between the LT and ST sequences (Clements, 1990). The ST epitopes were probably masked by folding of the LT-ST fusion peptide in the absence of the linker. In agreement with this work, the conformation assumed by the flagellin containing wild-type ST may mask the ST epitopes and the disruption of the two ST disulfide bonds may expose important ST determinants. This result was not expected, since the main reason for using an altered version of ST in this work was to reduce its toxic effect, as was previously described for the genetic fusion of the ST-decapeptide $\left(\mathrm{Cys}^{6}-\mathrm{Cys}^{15}\right)$ to the cholera toxin B-subunit, in which $\mathrm{Cys}^{7}$ was replaced by alanine, resulting in a non-toxic hybrid protein (Sanchez et al., 1988).

The absence of an immune response against ST in mice immunized orally with Salmonella expressing FLA-ST reflects the non-immunogenic nature of flagellin through this route. Previous data have shown that serum and mucosal antibody responses against flagellin and the foreign epitope could be obtained following oral immunization with live attenuated Salmonella (Wu et al., 1989). Recently, however, extensive work on the Salmonella/flagellin vaccine system presented evidence that flagellin does not represent an efficient carrier for heterologous epitopes by the oral route when delivered by live recombinant attenuated Salmonella strains (Almeida et al., 1999).

An alternative approach employed in this study to overcome the non-immunogenic nature of flagellin through oral immunization was to obtain the expression of flagellin inside the mammalian cells. Attenuated Salmonella strains have been shown to be able to deliver plasmid DNA inside eukaryotic cells and expression of the antigen in the cytosol of macrophages and dendritic cells induced the stimulation of different arms of the immune system (Darji et al., 1997; Sizemore et al., 1997). Here, we showed that a systemic antibody response against flagellin could be elicited in mice orally immunized with attenuated Salmonella delivering the plasmid encoding the flagellin gene with the mutated ST to mammalian cells. Because the titres against flagellin were relatively low, we did not expect to detect an antibody response against the ST toxin. Nevertheless, this seems to be a promising method to elicit an appropriate response against fusions to flagellin. En- 
hancement of the specific mucosal IgA immune response by expression of interleukin-5 by an attenuated Salmonella strain has been recently demonstrated (Whittle et al., 1997). Moreover, co-administration of interleukin expression vectors with a DNA immunogen has been demonstrated to improve cellular and humoral immune responses (Chow et al., 1997; Geissler et al., 1997; Xiang \& Ertl, 1995). The co-administration of vectors expressing interleukins and flagellin fusions delivered by attenuated Salmonella may improve the stimulation of a specific systemic and mucosal immune response against flagellin and heterologous antigen.

\section{ACKNOWLEDGEMENTS}

We wish to thank Dr A. M. Svennerholm for the kind gift of $\mathrm{ST}-\mathrm{CT}_{\mathrm{B}}$ conjugate, and Drs S. Newton and M. Rodrigues for helpful discussions. We thank Lucia Viotto posthumously for excellent technical assistance. C.M.P. was a recipient of a doctoral fellowship from CNPq. This work was supported in part by a WHO grant to B.E.C.G.

\section{REFERENCES}

Almeida, M. E. S., Newton, S. M. \& Ferreira, L. C. S. (1999). Lack of antibody responses against flagellin in mice orally immunized with live recombinant attenuated Salmonella vaccine strains. Arch Microbiol 172, 102-108.

Black, R. E. (1990). Epidemiology of traveller's diarrhea and relative importance of various pathogens. Rev Infect Dis 12, S73-S79.

Black, R. E. (1993). Epidemiology of diarrhoeal disease: implications for control by vaccines. Vaccine 11, 100-106.

Cárdenas, L. \& Clements, J. (1993). Development of mucosal protection against the heat-stable enterotoxin (ST) of Escherichia coli by oral immunization with a genetic fusion delivered by a bacterial vector. Infect Immun 61, 4629-4636.

Chow, Y.-H., Huang, W.-L., Chi, W.-K., Chu, Y.-D. \& Tao, M.-H. (1997). Improvement of hepatitis B virus DNA vaccines by plasmids coexpressing hepatitis B surface antigen and interleukin2. J Virol 71, 169-178.

Clements, J. D. (1990). Construction of a nontoxic fusion peptide for immunization against Escherichia coli strains that produce heat-labile and heat-stable enterotoxins. Infect Immun 58, 1159-1166.

Darji, A., Guzmán, C. A., Gerstel, B., Wachholz, P., Chakraborty, T. \& Weiss, S. (1997). Oral somatic transgene vaccination using attenuated S. typhimurium. Cell 91, 764-775.

Evans, D. G. \& Evans, D. J., Jr (1978). New surface associated heatlabile colonization factor antigen (CFA/II) produced by enterotoxigenic Escherichia coli of serogroups O6 and O8. Infect Immun 21, 638-647.

Geissler, M., Gesien, A., Tokushige, K. \& Wands, J. R. (1997). Enhancement of cellular and humoral immune responses to hepatitis $\mathrm{C}$ virus core protein using DNA-based vaccines augmented with cytokine-expressing plasmids. J Immunol 158, 1231-1237.

Giannella, R. A. (1976). Suckling mouse model for detection of heat-stable Escherichia coli enterotoxin: characteristics of the model. Infect Immun 14, 95-99.

Gomes, T. A. T., Rassi, V., MacDonald, K. L. \& 8 other authors (1991). Enteropathogens associated with acute diarrheal disease in urban infants in São Paulo, Brazil. J Infect Dis 164, 331-337.
Guth, B. E. C. \& Trabulsi, L. R. (1985). Evaluation of antisera used for detecting enterotoxigenic Escherichia coli in São Paulo. J Clin Microbiol 22, 626-628.

Hoiseth, S. K. \& Stocker, B. A. (1981). Aromatic-dependent Salmonella typhimurium are non-virulent and effective as live vaccines. Nature 291, 238-239.

Houghten, R. A., Ostresh, J. M. \& Klipstein, F. A. (1984). Chemical synthesis of an octadecapeptide with the biological and immunological properties of human heat-stable Escherichia coli enterotoxin. Eur J Biochem 145, 157-162.

Houghten, R. A., Engert, R. F., Ostresh, J. M., Hoffman, S. R. \& Klipstein, F. A. (1985). A completely synthetic toxoid vaccine containing Escherichia coli heat-stable toxin and antigenic determinants of the heat-labile toxin B subunit. Infect Immun 48, $735-740$.

Ibrahim, G. F., Fleet, G. H., Lyons, J. M. \& Walker, R. A. (1985). Method for the isolation of highly purified Salmonella flagellins. $J$ Clin Microbiol 22, 1040-1044.

Klipstein, F. A., Engert, R. F. \& Clements, J. D. (1982). Development of a vaccine of cross-linked heat-stable and heat-labile enterotoxins that protects against Escherichia coli producing either enterotoxin. Infect Immun 37, 550-557.

Klipstein, F. A., Engert, R. F., Clements, J. D. \& Houghten, R. A. (1983). Vaccine for enterotoxigenic Escherichia coli based on synthetic heat-stable toxin crossed-linked to the B subunit of heat-labile toxin. J Infect Dis 147, 318-326.

Newton, S. M. C., Jacob, C. O. \& Stocker, B. A. D. (1989). Immune response to cholera toxin epitope inserted in Salmonella flagellin. Science 244, 70-72.

Newton, S. M. C., Kotb, M., Poirier, T. P., Stocker, B. A. D. \& Beachey, E. H. (1991). Expression and immunogenicity of a streptococcal M protein epitope inserted in Salmonella flagellin. Infect Immun 59, 2158-2165.

Newton, S. M., Joys, T. M., Anderson, S. A., Kennedy, R. C., Hovi, M. E. \& Stocker, B. A. D. (1995). Expression and immunogenicity of an 18-residue epitope of HIV gp41 inserted in the flagellar protein of a Salmonella live vaccine. Res Microbiol 146, 203-216.

Okamoto, K., Okamoto, K., Yukitake, J., Kawamoto, Y. \& Miyama, A. (1987). Substitutions of cysteine residues of Escherichia coli heat-stable enterotoxin by oligonucleotide-direct mutagenesis. Infect Immun 5, 2121-2125.

Paglia, P., Medina, E., Arioli, I., Guzman, C. A. \& Colombo, M. P. (1998). Gene transfer in dendritic cells, induced by oral DNA vaccination with Salmonella typhimurium, results in protective immunity against a murine fibrosarcoma. Blood 92, 3172-3176.

Reis, M. H. L., Guth, B. E. C., Gomes, T. A. T., Murahovschi, J. \& Trabulsi, L. R. (1982). Frequency of Escherichia coli strains producing heat-labile toxin or heat-stable toxin or both in children with and without diarrhea in São Paulo. J Clin Microbiol 15, 1062-1064.

Saarilahti, H. T., Palva, E. T., Holmgren, J. \& Sanchez, J. (1989). Fusion of genes encoding Escherichia coli heat-stable enterotoxin and outer membrane protein OmpC. Infect Immun 57, 3663-3665.

Sanchez, J., Uhlin, B. E., Grundström, T., Holmgren, J. \& Hirst, T. R. (1986). Immunoactive chimeric ST-LT enterotoxins of Escherichia coli generated by in vitro gene fusion. FEBS Lett 208, 194-198.

Sanchez, J., Svennerholm, A.-M. \& Holmgren, J. (1988). Genetic fusion of a non-toxic heat-stable enterotoxin-related decapeptide antigen to cholera toxin B-subunit. FEBS Lett 241, 110-114.

Sanderson, K. E. \& Stocker, B. A. D. (1987). Salmonella typhimurium strains used in genetic analysis. In Escherichia coli and 
Salmonella typhimurium: Cellular and Molecular Biology, pp. 1220-1224. Edited by F. C. Neidhardt, J. L. Ingraham, K. B. Low, B. Magasanik, M. Schaechter \& H. E. Umbarger. Washington, DC: American Society for Microbiology.

Shimonishi, Y., Hidaka, Y., Koizumi, M., Hane, M., Aimoto, S., Takeda, T., Miwatani, T. \& Takeda, Y. (1987). Mode of disulfide bond formation of heat-stable enterotoxin $\left(\mathrm{ST}_{\mathrm{h}}\right)$ produced by a human strain of enterotoxigenic Escherichia coli. FEBS Lett 215, 165-170.

Sizemore, D. R., Branstrom, A. A. \& Sadoff, J. C. (1995). Attenuated Shigella as a DNA delivery vehicle for DNA mediated immunization. Science 270, 299-302.

Sizemore, D. R., Branstrom, A. A. \& Sadoff, J. C. (1997). Attenuated bacteria as a DNA delivery vehicle for DNA-mediated immunization. Vaccine 15, 804-807.

Svennerholm, A.-M., Wikström, M., Lindbland, M. \& Holmgren, J. (1986). Monoclonal antibodies against Escherichia coli heatstable toxin (STa) and their use in a diagnostic ST ganglioside GM1-enzyme linked immunosorbent assay. J Clin Microbiol 24, $585-590$

Towbin, H., Staehelin, T. \& Gordon, J. (1979). Electrophoretic transfer of proteins from polyacrylamide gels to nitrocellulose sheets: procedure and some applications. Proc Natl Acad Sci US A 76, 4350-4354.
Whittle, B. L., Smith, R. M., Matthaei, K. I., Young, I. G. \& Verma, N. K. (1997). Enhancement of the specific mucosal IgA response in vivo by interleukin-5 expressed by an attenuated strain of Salmonella serotype Dublin. J Med Microbiol 46, 1029-1038.

Wu, J. Y., Newton, S., Judo, A., Stocker, B. \& Robinson, W. S. (1989). Expression of immunogenic epitopes of hepatitis B surface antigen with hybrid flagellin proteins by a vaccine strain of Salmonella. Proc Natl Acad Sci U S A 86, 4726-4730.

Xiang, Z. \& Ertl, H. C. J. (1995). Manipulation of the immune response to a plasmid-encoded viral antigen by coinoculation with plasmids expressing cytokines. Immunity 2, 129-135.

Yamasaki, S., Hidaka, Y., Ito, H., Taked, Y. \& Shimonishi, Y. (1988). Structural requirements for the spatial structure and toxicity of heat-stable enterotoxin $\left(\mathrm{ST}_{h}\right)$ of enterotoxigenic Escherichia coli. Bull Chem Soc Jpn 61, 1701-1706.

Yoshimura, S., Ikemura, H., Watanabe, H., Aimoto, S., Shimonishi, Y., Hara, S., Takeda, T., Miwatani, T. \& Takeda, Y. (1985). Essential structure for full enterotoxigenic activity of heatstable enterotoxin produced by enterotoxigenic Escherichia coli. FEBS Lett 181, 138-142.

Received 9 May 2000; revised 30 October 2000; accepted 10 January 2001. 